\title{
Staff Participation in Management In Large University Libraries
}

\begin{abstract}
A CLR Fellowship in 1971-72 enabled the author to examine staff participation in the management of large academic libraries. The report considers the climate of participation, preparation given the staff, areas of decision making, the role of the professional staff association, and the reaction of staff to such participation.
\end{abstract}

\section{INTRODUCTION}

\section{$P$} ARTICIPATION BY LIBRARY STAFF in the management of the library basically involves representatives of the staff working in task-oriented groups to recommend possible solutions of library problems to the library administrators, to provide for a prescribed system of communication throughout the library, and to promote means for orderly change within the library system.

In the last twenty years libraries in large universities have grown very rapidly. As more books were purchased to serve a larger student body, more librarians were employed; yet the organization of the library remained basically the same. With the unrest on campus and the current social changes across the land in recent years, the library has not gone untouched.

Librarians have shown concern for their status on the campus and an interest in what was going on and why. Since staff size had precluded the informal staff meeting where real discussions could take place, some better way was needed for communication and an un-

Dr. Flener is associate librarian, University of California, Berkeley. derstanding of the library operation in order to make better decisions in increasingly complex situations.

Over the years there have been committees in libraries, both standing and ad hoc, which have provided staff opinion on a variety of subjects. It has been only in recent years, however, that a conscious effort has been made to include as many interested staff members as possible in the decision-making process. Informal groups have developed as librarians felt a need to discuss mutual problems. However, in order to best achieve the library goals and to bring the fullest use of the resources of the library to patrons, some system must be designed to cue the staff into what problems are under consideration, how the decision is to be made, and the resulting decision.

Recently there has been more in library literature related to problems of management based on theories of the behavioral sciences. Though most have been applied in the world of business, librarians have begun to study how these theories may be applied in library operations. With the aid of a Council on Library Resources Fellowship in 1971-72, the author sought to discover and understand staff-participation re- 
alities in the decision-making processes at ten large university libraries. ${ }^{\circ}$

\section{The Investigation}

The libraries selected were chosen because of staff size. It was felt that libraries with near 100 professional librarians had problems of a different order than those of lesser size. A large building with several separate departments plus branch libraries elsewhere on campus compounds the communication problem.

The aims of the site visits were to determine (1) the climate in which participation developed, (2) what preparation was given staff before moving into this kind of organization, (3) what areas in decision making seemed best suited to staff participation, (4) what role the professional staff association plays, and finally (5) what portion of the staff was interested in participation and, in general, the staff reaction to the value of staff participation in the decision-making process.

In each library interviews were held with the chief library administrators, as well as with department heads, branch librarians, and several below the unit head level.

\section{Climate for Participation}

The climate out of which staff-participation developed was a complex one. Communication problems were widespread, not only within the library system but also between the academic community and the library. Lack of recognition of librarians for their contribution to the academic community contributed to low morale. Discontent was prevalent due to lack of opportunity for expression on matters directly affecting their work. Outside the library, librarians seldom had a vote in the aca-

- The libraries visited are: Columbia, MIT, Cornell, Pennsylvania State, Stanford, University of California at Berkeley and at Los Angeles, Washington, North Carolina, and Duke. demic council. At Cornell and Columbia it was not deemed desirable to request faculty rank and title, or to be judged by faculty standards but by librarians' standards. However, at all institutions a voice in the academic council seemed generally desirable.

\section{Preparation for Participation}

Therefore learning to work in this context must be a developmental one. Only with the acceptance of the staff can even a partial success be accomplished. Librarians in general are not experienced in working in groups or conducting meetings. These skills must be learned and there must be constant effort to improve communication. (Cornell had a workshop on how to conduct a meeting.) Considerable responsibility is placed on the participating librarians. Working together in this way takes time before some people are willing to express themselves freely.

Libraries developing staff-participation programs have the traditional pyramidal organization charts. Plans for staff participation provide groups from various departments to work together. This is another overlay of organization providing an interdepartmental fertilization for staff input into decisions. There is horizontal as well as planned vertical communication through the organization of the staff.

Libraries have used committees for years to make recommendations for the solution of library problems, and such committees provide some background for staff participation. Some libraries had standing committees (administration-appointed) to deal with problems in broad areas such as personnel, collection development, technical, and public services. Building on this experience in group work, a system can be developed to give everyone interested an opportunity to contribute to the management of the library.

In all cases there was a considerable 
period of time during which the staff discussed and studied what seemed desirable in their own particular situation. Staff leadership, as well as that of the administration, plays a major role in determining how staff participation is established and how it functions.

Only at UCLA has the system for staff participation been operating long enough for a thorough evaluation. The consensus of the Evaluation Committee was that the concept of the Library Administrative Network, the UCLA plan for staff participation, had provided wide opportunities for staff participation and should be continued, with the addition of certain amendments based upon experience.

At UCLA in December 1966 the librarians sponsored a meeting to discuss the status of librarians in the University of California. The librarians realized the need to have established policy on such matters as job security, better promotion, grievance procedures, leaves of absence, access to research funds, opportunity for professional growth, salaries commensurate with faculty, and a voice in university and library affairs. The Staff Association, composed of both professional and nonprofessional staff members, had established in November 1964 an Ad Hoc Information Committee. In time, this committee recommended the establishment of a nonacademic personnel advisory committee. The general unrest in 1967 brought into focus recognition of the need for a study of the library's communication problems. Campus experts in the behavioral sciences and employeemanagement relations and the university librarians, with the approval of the Information Committee, employed a professional consultant to study the library's problems in depth. The report focused on the library as a social system, with emphasis on the human element. There followed a series of all-day meetings of the library unit heads, the ad- ministrative group, and two consultants with competence in team building and management, some twenty-five people, out of which developed a new structure and plans to review a number of functional committees with "communication" the most important problem.

The acceptance by the staff of the Library Administrative Network was established. Librarians learned to work in groups, to conduct meetings, and to record the ideas expressed in the meetings. Inherent in this plan is the responsibility of the librarians to work with other staff members on library problems and communicate their thoughts through an established line of communication.

Columbia, of course, is the subject of the widely-reported Booz, Allen \& Hamilton management study, with reorganization a possible outcome which would establish ways for participation by the staff.

At Cornell, as another example, a doctoral candidate in behavioral management interviewed fifty-five members of the professional staff to learn as much as possible about organizational behavior in the library. Staff reaction to the recently-established plan for staff participation was noted, though the plan had barely had time to be fully understood or the impact observed from this change. Recommendations for strengthening the staff participation included inhouse workshops on management theory.

\section{Principal Areas for Participation}

Apparently the most successful task oriented group in many libraries where staff were involved was the personnel. committee. Responsibility for determining criteria for promotion and recommending individuals who had met this criteria has worked well. In the few areas of disagreement, consensus was achieved between the committee and the library administration.

Staff participated in decisions related 
to public and technical services quite satisfactorily. Cornell used these techniques to reorganize the order department, taking a little over a year. Committees need to have a clear charge, or much time is wasted trying to determine purpose. Those with more general charges find themselves discussing areas outside their purview, overlapping other committee responsibilities.

\section{Role of the Staff Association in Participation}

Staff associations composed of the professional librarians came into being in the late 1960s. Prior to then, most libraries had a staff association composed of both professional and nonprofessional staff, which served primarily a social function. With changes in attitudes and the search for identity by librarians in academia, the professional staff association developed to provide an avenue for communication among the staff and a voice for the professional librarian. Through these channels many aspects of librarianship were discussed and recommendations made to library administrators, who, in turn, found this organization a way to secure staff reaction to many situations. Administrators have been learning ways of working with the staff associations. In some libraries they seem to be used as an arm of the administration as well as a sounding board for ideas. Some staff associations recommend persons for administratively appointed committees, some work at staff development and programs for orientation. In a few libraries it is not always easy to tell administrative committees from staff association committees. When functioning well, there is good communication. In some libraries the professional staff association appears to be the forerunner of an administration-established structure for staff participation in management.

Task-oriented groups with carefully drawn guidelines seemed most success- ful. The areas of personnel, technical, and public services appeared best suited for such a process. Budget making seemed unsuitable for the usual pattern of staff participation.

\section{Staff Interest in Participation}

In most libraries less than 50 percent of the staff seemed interested. Some people, after observing for a time, grew interested; others felt the scheme only a palliative, and considered it a waste of time. The opinion was expressed, "I like what I am doing and feel it more important than sitting in committees hour after hour." As was to be expected, in no instance was there full approval of staff-participation. Supporting staff were involved where their experience was appropriate. Opinions ran from full support of staff involvement regardless of the time it takes, to those who thought administrators were paid to make decisions and should do so. A number voiced the opinion that it was such a waste of time to have to educate the inexperienced in a group when a few knowledgeable people could have arrived at a good decision in a much shorter time.

However, there seemed to be a portion of the "old line" department heads who felt this interaction had done much, not only for the morale, but for breadth of understanding and insight into the responsibilities of the library overall. Though it is sometimes tedious to have to explain a complex situation to a new member of a committee, such effort contributes to the development of the staff as a whole.

Most younger librarians were reasonably enthusiastic. Some had soon found their particular jobs easily mastered and felt involvement to be an opportunity for growth and learning about what goes on in libraries. The opportunity to meet other young librarians in the system and see what kinds of positions they held was felt to be rewarding. By 
having on some committees the experienced librarian, each can observe different viewpoints.

\section{Staff Reaction to Participation in Decision Making}

Quite a large portion of the staff did not participate-some for personal reasons, some for lack of interest, some who did not want to take the time from their duties, and some who philosophically disagreed with the concept. A few administrators seemed to feel that at least a part of this unwillingness to participate was a lack of clear understanding of the process and that, in time, should the system prove itself, wider participation could be gained. Not being personally involved did not mean that they were not benefiting, for many of their colleagues passed along information gained through participation.

For the most part, the staff members interviewed had been active participants in the process. There was some negative response in every library, but overall it was considered worth the time and the feeling that the longer they engaged in this process and learned more about working together, the more rewarding it could become. The library administrators generally seemed to feel the need for staff recommendations on a wide range of problems before making a decision. There was never a question but that the final decision is the responsibility of the head librarian.

Among the libraries whose progress will be noted with special interest will be Columbia, Cornell, and UCLA. The report of the BAH survey at Columbia could have a major impact on other libraries. Cornell and UCLA both have been working with management consultants and are moving ahead seemingly with more direction.

\section{Conclusions}

From these visits, it seems clear that staff participation will play a larger part in library administration than in the past. Staff participation is nothing new in libraries, but the effort to involve all interested staff in contributing to the management of the library is the recent development. The real impact is yet to be felt. Librarians need to learn how to work in this manner. Every library visited had staff-participation to some degree. The degree seemed to hinge not only on the attitude and personality of the administration but also on the dynamism and leadership within the staff. Ahead lies the challenge of how best to establish the climate and communications necessary to use most effectively the talents within the staff to meet the changes ahead for libraries and their patrons. 